DOI 10.4467/25439561KSR.21.012.14423

\author{
BARTŁOMIEJ BRĄŻKIEWICZ \\ https://orcid.org/0000-0003-2223-8151 \\ Uniwersytet Jagielloński \\ Kraków
}

\title{
DECYZYJNA NIEDYSPOZYCJA. NIEKTÓRE OBLICZA RELATYWIZMU W WYBRANYCH UTWORACH PROZATORSKICH JEGORA FIETISOWA
}

\author{
DECISION-MAKING INDISPOSITION. \\ SOME FEATURES OF RELATIVISM IN SELECTED PROSE WORKS \\ BY EGOR FETISOV
}

\begin{abstract}
Streszczenie
Najnowsza proza rosyjska, wpisująca się w nieco szerzej ujmowaną literacką ,współczesność”, daje wyraz powszechności problemów ,pokoleniowych” zakorzenionych w ludzkich lękach, kłopotach tożsamościowych, zagubieniu i poczuciu samotności. Na przykładzie analizy dwóch wpisujących się w koncepcję petersburskiego tekstu literatury rosyjskiej powieści autorstwa Jegora Fietisowa widać, jak bardzo związane są one z kwestiami egzystencjalnymi. Odzwierciedlone w powieściowych dialogach rozważania mają charakter ideowy i są zorientowane wokół dramatyzmu wyborów, wolności i odpowiedzialności, gry pozorów, życiowego autentyzmu, a także zdystansowania względem „narzucanego”. Ich podstawowe przesłanie dotyczy zaś ,decyzyjnej niedyspozycji”, jako swego rodzaju niemocy przeżywanej w obliczu konieczności dokonania wyboru. Problem, stanowiący jedno z kluczowych doświadczeń ludzkiej subiektywności, typowy dla „współczesności”, w omawianych utworach często bywa relatywizowany.
\end{abstract}

Abstract

The newest Russian prose fiction, codified within more extensively labelled "contemporary" literature, expresses the universality of generational problems rooted in human fears, self-identity problems, numerous confusions and a sense of loneliness. The analysis of two 
novels by Egor Fetisov fitting into the concept of Petersburg text of Russian literature, shows their proximity to existential issues. The considerations reflected in the dialogues of the novels' characters are ideologically oriented, with reference to such questions as the drama of choices to make, freedom and responsibility, a game of appearances, authenticity in life, as well as some distancing from "the imposed." The central message of the novels concerns the "decision-making indisposition" seen as a kind of powerlessness experienced in the face of necessity to make a choice. The problem, constituting one of the key experiences of human subjectivity and typical of "present-day," is often relativised in the discussed novels.

Słowa kluczowe: literatura rosyjska, proza rosyjska, petersburski tekst literatury rosyjskiej, problemy egzystencjalne, Jegor Fietisow

Keywords: Russian literature, Russian prose-fiction, Petersburg text in Russian literature, existential issues, Egor Fetisov

W oglądzie współczesnej literatury rosyjskiej, tak jak dawniej, również obecnie na pierwszy plan wysuwają się utwory prozatorskie - w szczególności powieściowe. Próba drobiazgowej analizy kanonu współczesnej prozy rosyjskiej musi prowadzić do schematycznego zaledwie opisu przedmiotu badań, a to za sprawą trudności wynikających z dwóch podstawowych przesłanek.

Pierwszą z nich jest brak jasności odnośnie do zakreślenia ram czasowych „współczesności” w ogóle. Przyjmuje się tu dość umowne kryteria datacji, dolną granicę płynnie przesuwając od czasów pieriestrojki coraz bliżej dnia dzisiejszego, ostatnio aż po rok $2000^{1}$. Odnośnie do współczesnej rosyjskiej beletrystyki utarł się też podział na dwa zasadnicze nurty: postmodernizm i nowy realizm (czasem określany mianem „najnowszego" - новый реализм / новейший реализм²). Ponieważ oba one różnią się od swych zachodnich odpowiedników, to i aktualność tak jednoznacznej ich klasyfikacji może budzić wątpliwości. Problem ów szczególnie widoczny staje się w kontekście analizy utworów powstałych stosunkowo niedawno, już w XXI wieku, gdzie właściwe rosyjskiej odmianie nowego realizmu motywy ujmuje się w formie typowej dla postmodernizmu. Rosyjska krytyka literacka wskazuje też na obecność w prozie tendencji neosentymentalnych, egzystencjalnych oraz nostalgicznych, głównie począwszy od drugiej dekady trzeciego tysiąclecia. Na tak

${ }^{1}$ Zob. J. Sałajczykowa, Dziesięciolecie przemian. Proza rosyjska lat 1985-1995, Gdańsk, Wydawnictwo Uniwersytetu Gdańskiego, 1998; A. Wołodźko-Butkiewicz, Od pieriestrojki do laboratoriów netliteratury. Przemiany we współczesnej prozie rosyjskiej, Warszawa, Studia Rossica, 2004; K.A. Duda, Szkice o prozie rosyjskiej XXI wieku: Ulicka, Szyszkin, Pielewin, Minajew, Sienczyn, Kuricyn, Starobiniec..., Kraków, Księgarnia Akademicka, 2017, s. 10.

${ }^{2}$ Zob. А. Большакова, Феноменология литературного письма. О прозе Бориса Евсеева, Москва, МАКС Пресс, 2004, s. 10. 
zróżnicowanym podłożu pojawiają się zatem utwory rozmaicie porządkowane pod kątem reprezentowanego nurtu literackiego, w sensie genologicznym mocno zróżnicowane, niejednorodne pod względem tematycznym, zaś w wymiarze estetycznym - nierówne. Znajdą się wśród nich powieści polityczne, historyczne, wojenne, społeczno-obyczajowe i filozoficzno-społeczne, proza religijna, literatura science fiction i fantasy, kryminały itp.

Za drugą, utrudniającą całościowy ogląd współczesnej rosyjskiej literatury przesłankę, uznać należy ogromną liczbę publikowanych w Rosji rokrocznie książek. Według danych Rosyjskiej Izby Książki, w roku 2019 ogółem wydano drukiem 115171 tytułów, z czego 12203 woluminów zaliczono do kategorii „rosyjska literatura piękna" (w roku 2020, pandemicznym, zaobserwowano niewielki spadek tych wartości, do odpowiednio: 99857 i 11061$)^{3}$. W sytuacji silnie rozbudowanego i prężnie w Rosji działającego rynku książki, pojawiły się próby systematyzowania powstających współcześnie utworów w oparciu o dodatkowe kryteria - wśród nich: pokoleniowe, ideologiczne, płci, czy, zgodnie z „tekstologiczną koncepcją kultury rosyjskiej", która, jak powiada jej twórca, Aleksandr Lusyj, stanowi ni mniej, ni więcej, tylko sumę tekstów lokalnych - kryterium regionalne. Stąd podział na prozę syberyjska, kaukaską, uralską, moskiewską czy petersburską ${ }^{4}$.

W efekcie tak szerokiego spektrum analitycznego ujawniają się wielopłaszczyznowe, asymetryczne wiązania, nieraz ujawniające wewnętrzną niespójność dzieła literackiego. Oczywiście, powstające współcześnie teksty można poddawać klasyfikacji w oparciu o zaiste drobiazgowe instrumentarium pojęciowe, identyfikując, bez cienia ironii, utwór „X” jako „neosentymentalną, moskiewska, kobiecą powieść obyczajową". Podobne zabiegi przysporzyć moga jednak nad wyraz jałowych sporów typologicznych i bezproduktywnych polemik, które, nie dość, że nie przynoszą definitywnych rozstrzygnięć, to dodatkowo usuwają z pola widzenia obiekt rozważań.

Ujawniając sensy, będące częścią składową najnowszej prozy rosyjskiej, wypada poczynić pewne nawiązanie do bachtinowskiej koncepcji dialogiczności, zwracając w głównej mierze uwagę na ideową aktualizację człowieka mówiącego w utworze literackim, jako na nosiciela pewnej idei, przedstawiciela określonego poglądu na świat ${ }^{5}$. Według Michaiła Bachtina, podobna perspektywa przyjmuje postać analiz, których sedno, będące zarazem głównym przedmiotem samej powieści - stanowi

${ }^{3}$ Szczegółowe statystyki, począwszy od roku 2012, można prześledzić na stronie internetowej Rosyjskiej Izby Książki, wcześniej wydawane one były w formie drukowanej. Zob. Cтатистические показатели по выпуску печатных изданий, Российская книжная палата, Филиал ИТАР-ТАСС, [w:] http://www.bookchamber.ru/statistics.html [dostęp: 30.05.2021].

${ }^{4}$ Zob. А.П. Люсый, Московский текст: текстологическая концепция русской культуры, Москва, Издательский дом „Вече”, ООО „Русский импульс”, 2013.

${ }^{5}$ Zob. M. Bachtin, Stowo w powieści, [w:] Idem, Problemy literatury i estetyki, thum. W. CeslukGrajewski, Warszawa, Czytelnik, 1982, ss. 171-172. 
prawie zawsze ideolog i jego ideologem, inaczej: wypowiedź ideologiczna ${ }^{6}$. „Эта идеологема - интертекстовая функция" nia się w efekcie dostrzeżenia analogii utworu literackiego do repliki dialogu, który przecież ,jest obliczony na odpowiedź innego człowieka (albo: innych ludzi), na jego aktywne, współodpowiadające rozumienie"s. Rolę niebagatelną odgrywają tu, tak zwane, „czyste dialogi”. W ujęciu Bachtina nie są one wyłącznie kolejnym elementem kompozycyjnym utworu, nie tylko organizują fabułę, lecz - co najważniejsze - sprzyjają przedstawieniu ideologicznych światów mówiących bohaterów9 Autor Problemów poetyki Dostojewskiego (Проблемы поэтики Достоевского) z całą mocą podkreśla:

„[...] idea jest interindywidualna $\mathrm{i}$ intersubiektywna, sfera jej bytowania - to nie indywidualna świadomość, lecz dialogowe obcowanie pomiędzy świadomościami. Idea - to żywe wydarzenie, rozgrywające się przy dialogowym spotkaniu dwóch czy kilku świadomości”’10.

W rzeczy samej, w najnowszej rosyjskiej prozie czyste dialogi najczęściej służą właśnie jako platforma, na której mają szansę zaistnieć treści ideowe. Unikając nawarstwienia wymiarów pojęciowych, których w bachtinowskiej metodzie interpretacyjnej nie brakuje, można w tym miejscu wykorzystać nomenklaturę właściwą komunikacyjnemu podejściu do tekstów literackich. „Zdolność widzenia paradoksów naszego istnienia, umiejętność postrzegania tych samych zjawisk z różnych perspektyw, wyjścia poza stereotypy" "11, wyeksponowane w dialogach treści ideowe - obserwacje, przemyślenia czy prawdy, które u odbiorcy wywołują np. potrzebę odpowiedzi na pytania o sens jego istnienia, reprezentujący orientację komunikacyjną badacze nazywają po prostu „przeżywaniem mądrości” ${ }^{12}$. Jego podstawę stanowi zaś podatność odbiorcy do podjęcia refleksji nad wywołującymi emocje, przeżycia estetyczne, treściami.

${ }^{6}$ Zob. H. Markiewicz, Polifonia, dialogiczność i dialektyka. Bachtinowska teoria powieści, „Pamiętnik Literacki” 1985, nr 76/2, s. 92.

${ }^{7}$ А.П. Люсый, Поэтика предвосхищения. Россия сквозь призму литературы, литература сквозь призму культурологии: теоретическая комедия, Москва, Товарищество научных изданий КМК, 2011, s. 167.

${ }^{8}$ M. Bachtin, Estetyka twórczości stownej, tłum. D. Ulicka, oprac. przekładu i wstęp E. Czaplejewicz, Warszawa, PIW, 1986, s. 369.

${ }^{9}$ Zob. M. Bachtin, Stowo w powieści..., op.cit., ss. 209-210.

${ }^{10}$ M. Bachtin, Problemy poetyki Dostojewskiego, thum. N. Modzelewska, Warszawa, PIW, 1970, ss. $133-134$.

${ }^{11}$ A. Awdiejew, G. Habrajska, Wprowadzenie do gramatyki komunikacyjnej, t. 2, Łask, Oficyna Wydawnicza LEKSEM, 2006, s. 294.

${ }^{12}$ Ibidem. 
Bez nadmiernej przesady można stwierdzić, że najnowsza proza rosyjska, szczególnie zaś utwory powstałe po roku 2000, jest wyrazistym świadectwem niestabilnego stanu ducha całego pokolenia. Temat, który wypromował Wiktor Pielewin wraz z powieścią Generation „, $P$ ” (Generation „П”, 1999), w latach następnych przybrał formę w sposób zdecydowanie pesymistyczny ukazującą zdystansowane względem radzieckiego dziedzictwa, a zarazem unikające konfrontacji z teraźniejszością i nieradzące sobie z wyzwaniami jutra, pełne niepokojów o własną przyszłość postaci literackie. Przygnębiająca wahliwość bohaterów oraz wtórujące jej wielkie znaki zapytania, ujawniają rozczarowanie kierunkiem, w jakim zmierza Rosja początku nowego tysiąclecia, przemianami zachodzącymi w życiu społecznym i politycznym kraju, zwłaszcza zanikiem poczucia życia w historii, bycia jej częścią, jej uczestnikiem, co stanowi ideową dominantę wielu utworów. Towarzyszące bohaterom problemy samoidentyfikacyjne mają ponadto związek ze wszechogarniającym poczuciem zbędności, wyobcowania, bylejakości na tle państwa, postrzeganego w kategoriach troszczącej się wyłącznie o własne interesy korporacji, co jedynie potęguje i tak już dystansującą wszystkie pozostałe - postawę bierności. Tak widziana współczesność, czy inaczej - teraźniejszość, świadomość bycia trybikiem w machinie, wprowadza bohaterów w świat pełen sprzeczności; niesie za sobą, z jednej strony, sprzeciw wobec takiego stanu rzeczy, z drugiej zaś nieumiejętność wybicia się ponad rzeczywistość, w której polityka i gospodarka do sprawnego funkcjonowania nie potrzebują aktywnego i kreatywnego indywiduum, prędzej jednostkę zaklinowaną w szczelinie między stanem depresyjno-lękowym a lękami nerwicowymi.

Jednym $\mathrm{z}$ autorów współtworzących obraz najnowszej rosyjskiej prozy o wydźwięku zbliżonym do wyżej zasygnalizowanego jest Jegor Fietisow (ur. 1977). Literacką karierę autor rozpoczął w drugiej dekadzie XXI w., początkowo koncentrując się na twórczości poetyckiej, w późniejszym okresie publikując również małe formy prozatorskie, głównie w rosyjskich czasopismach literackich („Нева”, „Арион”, „Под небом единым”, „Новый Берег”, „Знамя”, „Звезда”, „Урал”, „Октябрь”) oraz pracach zbiorowych. Na potrzeby niniejszego tekstu analizie poddane zostana dwie powieści autorstwa Fietisowa, bez dodatkowych przymiotników, choć obie, bez wątpienia, wpisujące się w opracowaną przez Władimira Toporowa koncepcję tekstu petersburskiego ${ }^{13}$.

Pierwsza z nich pochodzi z roku 2014 i nosi tytuł Пас в nycmomy ${ }^{14}$. Ze względu na niejednoznaczność słówka „паc”, przytoczenie polskiego wariantu tytułu może

${ }^{13}$ Zob. B.Н. Топоров, Петербургский текст русской литературы, Санкт-Петербург, Искусство-СПБ, 2003, s. 22; В. Brążkiewicz, $W$ zderzeniu z teraźniejszościq. Dialogiczność współczesnej prozy petersburskiej, „Ethos” 2020, nr 1(129), s. 96.

${ }^{14}$ Е. Фетисов, Пас в пустоту, Санкт-Петербург, Издательство «Союз писателей Петербурга», 2014. 
sprawiać pewne problemy. Użyta tu konstrukcja językowa („пас в пустоту”) wуwodzi się z terminologii piłkarskiej i oznacza „nieudane podanie”, tj. utratę piłki wskutek podania do zawodnika, który nie jest w stanie jej przejąć. Można byłoby pójść w tym kierunku i „nieudane podanie” uznać za alegorię wyzwania, któremu bohater nie jest w stanie sprostać, niewykorzystaną okazję. Niemniej, wbrew temu, co mogłaby sugerować umieszczona na okładce ilustracja, płaszczyznę semantyczną utworu wyznacza Wielkanoc, a więc symboliczny okres ,przejścia”, dlatego proponuję przyjąć thumaczenie ,przejście w pustkę”.

W centrum przesyconego treściami filozoficznymi tekstu umieścił Fietisow dwudziestosześcioletniego Fiodora Sosnina, który wypowiada w powieści większość kwestii o zabarwieniu ideowym. Bohater, do niedawna wykładowca języka niemieckiego w petersburskim konserwatorium (władze uczelni zdecydowały o nieprzedłużeniu umowy o pracę) stoi u progu wielkich, życiowych zmian. Ma wkrótce opuścić rodzinny Petersburg i wyjechać do Niemiec, gdzie zamierza doskonalić umiejętności piłkarskie w jednym z tamtejszych klubów sportowych. Choć decyzja już zapadła, możliwe konsekwencje dokonanego wyboru wciąż zaburzają w nim poczucie równowagi. Na jednej szali bohater waży niewątpliwe korzyści płynące ze zmiany miejsca zamieszkania, drugą obciąża wszystko to, za czym Fiodor tęsknić będzie najbardziej, czyli spotkania i rozmowy o muzyce z ludźmi, którzy się na niej znają. Wewnętrzne rozdarcie bohatera potęguje dodatkowo lęk o przyszłość uczuciowego związku z niedawno poznaną Maszą.

Zbliżające się święta Wielkiejnocy mobilizują Fiodora do odwiedzenia krewnych mieszkających na wsi, gdzie bierze udział w tradycyjnym przedświątecznym polowaniu na kaczki. Zabijanie niewinnych zwierząt - czyn grzeszny, jak zwyczajowe łowy określiła ciotka Fiodora, zostaje okupiony wywołującym u głównego bohatera zapalenie mózgu ukąszeniem kleszcza. Intoksykacja zwiastuje cierpienie - okres nieznośnych bólów głowy i gorączkę, które prowadzą Fiodora do równie wyczerpujących rozmyślań dotyczących istoty paschalnego misterium:

„Песах, - прошептал Фёдор, с трудом разжав побелевшие от страха губы, - песах. Это же форма прошедшего времени, - подумал он тут же, она означает «прошёл», а мне нужно «пройди», как же сказать пройди, как он спрягается, этот дурацкий глагол $[\ldots] ", 15$.

Stan chorobowy, symbolizujący śmierć bohatera, uzupełniają wspomnienie ojca - lekarza, który zmarł w Afryce na malarię, gdy Fiodor był jeszcze dzieckiem, oraz uczestnictwo w pogrzebie bliskiej osoby. Do Fiodora dociera wówczas, że ostatnia

${ }^{15}$ Ibidem, s. 222. 
posługa, z punktu widzenia nieboszczyka, w gruncie rzeczy nie ma znaczenia. Zmarłemu jest już obojętne, czy pochowają go w trumnie czy w urnie po kremacji. Ceremonia w istocie służyć ma żyjącym, jako przesłanka do zastanowienia się nad sensem życia i przyjmowanych przez żałobników postaw. Swoje poglądy Fiodor wyraża w dialogach z Maszą, która mówi o sobie, że niewiele rozumie, na filozofii się nie zna, czytać wprawdzie potrafi, ale widzi tylko to, co znajduje się na powierzchni tekstu i ogólnie ma się za dziewczynę niewykształconą, bo nie ukończyła studiów. Cmentarna atmosfera skłania Fiodora do wyartykułowania retorycznego jego zdaniem pytania:

„,- Какими были бы поступки Иисуса, если бы он был не Сыном, а отцом, мужем? Если бы крест на Голгофу нёс не он сам, а его дочь? Если бы жирные, тупые, самодовольные скоты измывались над ней, травили её, как собаку? Что делать родителям молодых любящих друг друга людей, которых пьяный провинциональный депутат размазал своим джипом по асфальту - подставить другую щёку? Привести ему ещё детей, чтобы он пожрал их? Или прав Ницше, который сказал, что благодаря христианству такие свиньи получили свою депутатскую неприкосновенность?

- Так и сказал? - рассмеялась Маша.

- Несколько другими словами, но смысл этот [...]”16.

$\mathrm{Z}$ jednej strony Fiodor nie może się pogodzić ze światem pozorów, którego kwintesencję stanowi dlań Rosja; ułuda, fałsz i wszechobecne krętactwa, powszechna względność postaw przypominały mu obraz znany z konserwatorium. Mówi:

„Консерватория представляла собой Россию в миниатюре. Всё те же две стороны: одна - парадная, с мраморной лестницей и отремонтированным органом, другая - скрытая от любопытствующего взгляда, подлинная сторона чёрных лестниц, на которых с утра до вечера курят и трубят на духовых инструментах студенты и, как улитки, ползают преподаватели, не имеющие своего угла" ${ }^{\text {"17. }}$

W jego wypowiedzi pobrzmiewały niejako odniesienia do potiomkinowskich wiosek albo wspomnienie słów markiza de Custine o ukrytej za piękną fasadą prawdziwej naturze Imperium Rosyjskiego, którego mieszkańcy „Tak nalegają, abyśmy do nich przyjeżdżali w zimie: sześć stóp śniegu zakryłoby wszystko, latem natomiast widzimy, jak to wygląda"18.

${ }^{16}$ Ibidem, ss. 207-208.

${ }^{17}$ Ibidem, s. 6.

${ }^{18}$ A. de Custine, Listy z Rosji. Rosja w 1839 roku, tłum. M. Górski, Kraków, Wydawnictwo Aramis, 1989, s. 40. 
Z drugiej zaś strony Fiodor dostrzega w sobie brak zdecydowania, niespójność, niejednoznaczność, niestałość, tymczasowość, brak zakorzenienia, mając zarazem do siebie o to wszystko pretensje, choć do końca nie wie, czy słusznie, bo może to „okoliczności”, „obecne czasy” sprawiają że tak mu trudno odnaleźć się w otaczającej go rzeczywistości:

„Ты пойми, я же не за деньгами бегу, не куда, а откуда. Пока я рос, дом, в котором я жил, превратился в гостиницу. Ты видела этих людей? - Фёдор, сам того не желая, завёлся, - хочешь, поищем коренного горожанина?"'19

Masza widzi to zgoła inaczej, akceptuje teraźniejszość, nie walczy z nią, poddaje się jej, a frustrujące Fiodora spostrzeżenia na temat otaczającego ich świata zdaje się postrzegać w kategoriach normy:

„- Фёдор, но в Европе сейчас то же самое, мы не исключение: класс горожан понемногу исчезает. Все чуствуют себя везде проездом"20.

Po wyjeździe do Kolonii egzystencjalny pesymizm przeżywającego różnorakie lęki i niepokoje bohatera przerywa nagłe nasilenie objawów chorobowych. $\mathrm{Na}$ niedomagającego Fiodora już czeka przewoźnik, w malignie bohater o mały włos nie zapłacił za przekroczenie rzeki - do świata żywych wraca usłyszawszy słowo encephalitis. Łódź niemieckiego Charona odpływa więc bez pasażera, Fiodor z ulgą zaś, ściszonym głosem mówi: „Прошёл”21. Chodzi nie tyle o to, że anioł - a może demon - śmierci go oszczędził, lecz że sam Fiodor doświadcza osobliwego przejścia, powtórnych narodzin, zrywa z dawnym sobą. Sytuacja, w jakiej się znalazł, nie służy jednak zarysowaniu nowych granic własnego ,ja”. Poszukiwanie, czy tworzenie nowej tożsamości byłoby niczym innym, jak tylko próbą ustanowienia innej, równie skostniałej struktury osobowościowej. Oświecenie, którego doznaje główny bohater, jest odpowiedzią na próby, jakim poddaje go współczesna, patchworkowa rzeczywistość. Podsumowując owe doświadczenia językiem psychologii kultury:

„Zderzenie ze światem - implozja, pozbawia nas tożsamości, by tym samym nazwać ją Pustką. W procesie petryfikacji, czyli lęku przed zamienieniem się w kamień, strachu, poprzez który stajemy się tym kamieniem, czy prób «skamienienia» innego człowieka mamy kolejne przesunięcia granic"22.

\footnotetext{
${ }^{19}$ Е. Фетисов, Пас в пустоту ..., ор.cit., s. 92.

${ }^{20}$ Ibidem.

${ }^{21}$ Ibidem, s. 237.

${ }^{22}$ A. Pankalla, Doświadczenia graniczne, [w:] Z.W. Dudek, A. Pankalla, Psychologia kultury. Doświadczenia graniczne i transkulturowe, Warszawa, ENETEIA, 2005, s. 99.
} 
Powieść Fietisowa traktuje o takim właśnie „przejściu w pustkę”. Dla głównego bohatera oznacza ono przede wszystkim konieczność przyjęcia nieskończenie otwartej postawy względem wyzwań, jakie stawia przed nim błyskawicznie, a zarazem nierównomiernie zmieniający się, nieprzewidywalny świat; niezamykanie się na to, co może przynieść życie. Godny uwagi jest też fakt, że kluczowe z punktu widzenia wymowy utworu przemyślenia pojawiają się po pierwsze jako echo rozmów Fiodora z Maszą - dziewczyną nieskomplikowaną, przeżywającą otaczającą ją rzeczywistość w sposób autentyczny, życie biorącą takim, jakie ono jest, wolną od ograniczających egzystencję norm, która nijak nie sili się na filozoficzne debaty; po drugie, że uwidaczniają się one na tle chorobowym. Tak, jakby zdolność refleksji człowieka zdrowego ograniczały jakieś wewnętrzne lub zewnętrzne czynniki, towarzyszące mu lęki były thumione, a jedynym bodźcem ośmielającym bohatera do wypowiadania skłaniających do zadumy komunikatów, usprawiedliwiającym ich zaistnienie, była choroba. Analogicznie do wynikającej z czaadajewowskiej Apologii obtakanego (Апология сумасшедшего, 1837) konkluzji - zgody na stygmatyzującą diagnozę, gdy tylko etykieta szaleńca daje obywatelowi prawo do wygłaszania kontrowersyjnych poglądów ${ }^{23}$.

Nieco bardziej zawiła jest fabuła drugiej powieści Fietisowa, zatytułowanej Arka (Ковчег, 2016) ${ }^{24}$. Akcja utworu rozgrywa się w Petersburgu, w typowych dla Północnej Stolicy okolicznościach przyrody. W zarysie: nad miastem skłębiły się ciemne chmury, bez przerwy pada deszcz, a jakby tego było mało, szwankuje sieć komórkowa, co w wyraźny sposób utrudnia mieszkańcom kontakt ze światem. Jest to kwestia nie bez znaczenia zważywszy, że równocześnie zamknięto wszystkie drogi wyjazdowe z Petersburga - chodzą bowiem słuchy, że do miasta przedostał się śmiercionośny wirus, lada moment wybuchnie epidemia, a ludzkość czeka zagłada. Główny bohater - Matwiej Lamiechow, jest dyplomowanym artystą plastykiem, absolwentem petersburskiej „Muchy”, czyli Państwowej Akademii Sztuki i Wzornictwa Przemysłowego im. Stieglitza (w okresie radzieckim patronowała jej Wiera Muchina, dlatego uczelnię potocznie zwano „Muchą”, „Muchinką" albo „Muchenwaldem”, jej studentów zaś „muchinoidami” lub „muchomorami”25). Matwiej, zgodnie z wolą teścia, wybitnie rozczarowanego życiowymi wyborami córki, a jednocześnie korzystając z jego protekcji, został zmuszony do przyjęcia przynoszącej stałe i godziwe dochody posady kierownika zaopatrzenia w miejskim cyrku, co równało się rezygnacji z pielęgnowania artystycznych pasji.

${ }^{23}$ Zob. B. Brążkiewicz, Choroba psychiczna w literaturze i kulturze rosyjskiej, Kraków, Księgarnia Akademicka, 2011, ss. 163-164.

${ }^{24}$ Zob. Е.С. Фетисов, Ковчег, Москва, Время, 2018.

${ }^{25}$ Zob. hasła: Муха, Мухенвальд, Мухиноиды, Мухинка, Мухоморы, [w:] Н.А. Синдаловский, Словарь петербуржиа. Лексикон Северной столиць. История и современность, Москва, СанктПетербург, Издательство Центрполиграф, Русская тройка-Спб, 2014, ss. 183-184. 
W sensie ideowym motyw przewodni tego utworu osnuty jest wokół problemu dokonywania wyborów. Myśl o niechybnej utracie wolności twórczej w zestawieniu z czekającym go nudnym, uporządkowanym i zrytualizowanym życiem rodzinnym, nastraja Matwieja pesymistycznie. Towarzyszące rozmyślaniom nad nędzą własnego losu smutki bohater postanawia utopić w alkoholu i, w poszukiwaniu towarzystwa, odwiedza „Bezpańskiego Psa”26 - funkcjonujący pod historyczną nazwą i w niegdysiejszym miejscu współczesny lokal. Dziwnym zrządzeniem losu trafia jednak do przedrewolucyjnej kawiarni literacko-artystycznej, spojonej z alternatywną płaszczyzną temporalną. Bohater chłonie tam odurzającą atmosferę miejsca spotkań petersburskiej bohemy i spotyka czołowych przedstawicieli srebrnego wieku - Nikołaja Gumilowa, Annę Achmatową, Władimira Narbuta, Bieniedikta Liwszyca, Wsiewołoda Meyerholda, Władimira Majakowskiego i oczywiście Osipa Mandelsztama. Ten ostatni, wypowiadając wiele stanowiących o myśli przewodniej utworu kwestii, w planie narracyjnym okazuje się być postacią kluczową. Zaprzątająca głównego bohatera myśl dotycząca podejmowania życiowych decyzji, w toku rozmowy z poetą-akmeistą przybiera formę pytań tyczących się sensu istnienia, celu sztuki, misji artysty, a w kontekście zagrażającej miastu katastrofy - rozważań nawiązujących również do istoty zbawienia. Wierzący bezkrytycznie, miejscami w sposób dosłowny wręcz pojmując zamysł budowania arki przetrwania, Matwiej zapytuje:

„-А вы... Вы верите в существование ковчега?

- Я верю в существование потопа, - мрачно пошутил Осип. - Ковчег - это и есть вечность, о которой мы говорили. Искусство, не знающее времени как категории. - Значит, чтобы спастись...

- Ковчег не спасательная шлюпка, - отрезал Осип. - Ковчег - это метафора строительства как такового. Каждый, понимаете, каждый должен строить свой ковчег. По крайней мере, каждый художник. Но не для того, чтобы болтаться по волнам и прибиться потом к горе Арарат. А потому что само созидание - и есть ковчег. Его строительство важно само по себе" 27 .

Zajmujące głównego bohatera problemy Mandelsztam sprowadza do artystycznego procesu twórczego. Twierdzi na przykład, że początek i koniec nie istnieją, albo inaczej - istnieją nierozdzielnie, ponieważ każdy początek jest zapowiedzią końca czegoś, jak narodziny niechybnie zwiastują śmierć. Toteż prawdziwą nieśmiertelność odnaleźć można tylko w świecie sztuki.

${ }^{26}$ Zob. C.C. Шульц (младший), B.А. Склярский, Бродячая собака. Век нынешний - век минувиий, Санкт-Петербург, Белое и Черное, 2002, s. 44.

${ }^{27}$ Е.С. Фетисов, Ковчег..., ор.cit., s. 90. 
Wszystkie dialogi poruszające problem istoty bytu ludzkiego, występują w rozdziałach konkretyzowanych na kanwie czasów minionych. Jakby intelektualne biesiady, rozmowy służące zamanifestowaniu postaw światopoglądowych zaistnieć mogły znów wyłącznie w świecie odrealnionym - tym razem w przeszłości, ponieważ teraźniejszość charakteryzują bezbarwne odcienie codzienności, sprawy banalne, przyziemne, jak - mieszkanie, praca, pieniądze itp.

Myśli o arce nie znikają ze stron utworu. Odbiorca słyszy na przykład, że naprawdę „Есть только камни, которые меняют форму и каждый раз складываются по-разному"28. Przywołany w tym kontekście motyw kamieni z jednej strony odpowiada estetycznym zapatrywaniom Mandelsztama, który słowa porównywał do kamieni, a sztukę poetycką do budowania. Dla poety, którego debiutancki zbiór wierszy nosił tytuł Kamień (Камень, 1913), paradoksalnie jedynym kryterium jedności literatury narodowej, jedyną wartością stałą był podlegający nieustannym zmianom język określonego narodu - wszystkie pozostałe kryteria zaś umowne, przejściowe i arbitralne ${ }^{29}$. Zgodnie z ideową wymową omawianego utworu, również z perspektywy Fietisowa „Budować znaczy walczyć z pustką”30 - i, jak dalej w swym poetyckim manifeście zapisał Mandelsztam: „Nie ma współzawodnictwa. Jest współudział istnień w spisku przeciw pustce i niebytowi" ${ }^{31}$. Tym sposobem Fietisow zdaje się wyrażać pogląd, jakoby każdy człowiek obowiązany był sam decydować o tym, czy w ogóle pragnie zbudować własną arkę, z czego i w jaki sposób, a nade wszystko czym chciałby ją zapełnić, jaką nadać jej treść. Tylko od niego zależy, jak rozłoży akcenty, bowiem nie każda wypowiedź, uczucie czy doświadczenie, nie wszystkie historyczne fakty człowiek decyduje sięutrwalić pismem albo obrazem. Zachowujemy jedynie te fragmenty rzeczywistości, które obecne pokolenie uznaje za dość ważne, by przekazać je następnej generacji, co ukazują prowadzone obecnie badania w kierunku tzw. „kultury pamięci” ${ }^{2}$. Po raz kolejny widać tu odwołanie do kwestii wyboru, o którym w jednej z końcowych scen Matwiej powie: „Самая чудовищная вещь в жизни - выбор" 33 . Zadanie rzeczywiście niełatwe, mierzy się z nim jednak każdy - co zachować, a co odrzucić, czym napełnić arkę? Tym bardziej, że - jak w kontekście „Bezpańskiego Psa”, postrzeganego jako swoista „arka artystów” początku ubiegłego wieku, powiada fikcyjny Dymitr Mereżkowski: „Однако никакой

${ }^{28}$ Ibidem, s. 89.

${ }^{29}$ Zob. O. Mandelsztam, O naturze słowa, [w:] Idem, Słowo i kultura. Szkice literackie, tłum. i oprac. R. Przybylski, Warszawa, Czytelnik, 1972, s. 27.

${ }^{30}$ O. Mandelsztam, Świt akmeizmu, [w:] Idem, Stowo i kultura ..., op.cit., ss. 183-184.

${ }^{31}$ Ibidem, s. 184.

${ }^{32}$ Zob. A. Erll, Kultura pamięci. Wprowadzenie, thum. A. Teperek, posł. i red. nauk. M. Saryusz-Wolska, Warszawa, Wydawnictwa Uniwersytetu Warszawskiego, Niemiecki Instytut Historyczny, 2018.

${ }^{33}$ Е.С. Фетисов, Ковчег..., ор.cit., s. 212. 
ковчег не вечен" 34 - trwały jest budulec, nie budowle. Z drugiej strony słowa wyimaginowanego Mandelsztama odnieść można do metafory „wędrujących kamieni”, jak Mieke Bal określiła interdyskursywność ${ }^{35}$. Główny bohater poszukuje niewzruszonego punktu odniesienia w ,płynnej nowoczesności”36, a jednocześnie odrzuca zastany porządek świata jako skamieniały. Jego chwiejność, nieokreśloność i brak zdecydowania, analogicznie do sensów uwidocznionych na przykładzie Fiodora z Przejścia $w$ pustkę, korespondują z obrazującym ów stan łacińskim aforyzmem Saxum volutum non obducitur musco - „kamień toczony mchem nie obrasta”.

Utwór Fietisowa sprawia wrażenie kolejnego pretekstu do rozważenia przez czytelnika kwestii luźno włączonych w nadrzędny porządek fabuły. Spośród sporej liczby kulturowych odniesień na plan pierwszy wysuwa się oczywiście starotestamentowa arka; warto jednak również zwrócić uwagę na symboliczne nazwisko głównego bohatera. Lamiechow (Ламехов) - czyli syn Lamecha (w polskiej transkrypcji często - Lameka) - powinien się stać współczesnym Noem. Chce budować arkę, lecz po to tylko, by uniknąć dosłownie ujmowanego potopu, czyli zagrażającej mieszkańcom miasta epidemii; w innym wymiarze po to jedynie, ażeby odpłynąć, uciec od prozy życia w wyimaginowany, a zarazem wyidealizowany obraz przeszłości. Staje się egzemplifikacją współczesnego, niezdecydowanego człowieka, który bojąc się ponieść odpowiedzialność za swoje czyny - nie dokonuje wyborów, daje się unosić falom; który, być może naiwnie wierzy w to, że świat jest dobry i bezpieczny, lecz za wszelką cenę, nie wiadomo nawet, czy świadomie, pragnie ochronić siebie i swoich bliskich przed rzeczywistością. Fietisow sugeruje, myśli te wkładając w usta Mereżkowskiego, że właśnie dlatego człowiek woli czuć nad sobą przymus szczególnie zakazującego, lub nakazującego, organizującego wszystkie sfery jego życia - prawa, a nie korzysta z wolności:

„,- Вы верите в Бога?

$[\ldots]$

- Не знаю.

- Если человек не верит в Бога, я не касаюсь сейчас вашего случая, то он верит в явления. Вы согласны?

Матвей кивнул.

- А явления по сравнению с божеством - это нечто срединное, усредненное. Отсюда и произрастает это измельчание и утрата индивидуальности. Вера нужна,

${ }^{34}$ Ibidem, s. 197.

${ }^{35}$ Zob. M. Bal, Narratologia. Wprowadzenie do teorii narracji, tłum. zespół tłumaczy ze specjalności przekładowej Instytutu Filologii Polskiej UAM w Poznaniu, Kraków, Wydawnictwo Uniwersytetu Jagiellońskiego, 2012, s. 71.

${ }^{36}$ Zob. Z. Bauman, Płynna nowoczesność, tłum. T. Kunz, Kraków, Wydawnictwo Literackie, 2006. 
Матвей, не ради загробной жизни или бессмертия, а ради вашей личности, которая без веры просто теряет масштаб.

- А искусство?

- Искусство - путь к свободе. Признание того, что Бог - это любовь и свобода, а не закон и порядок. Ветхозаветный Бог не потерпит творчества, потому что есть только один Творец. Так что берегите новозаветную веру. Без нее мы потеряем самое ценное, что у нас есть, - любовь, воплощенную в свободе"з7.

Obie powieści, mimo sporego zróżnicowania w zakresie doboru motywów tematycznych, cechuje pewien zestaw podobieństw. Za podstawowe, łączące je ogniwo, trzeba uznać uzewnętrznienie obudowanych dialogami postaw światopoglądowych. Znajdują się wśród nich kwestie społeczno-polityczne, zagadnienia natury filozoficznej, estetycznej, nade wszystko zaś towarzyszące bohaterom trudności samoidentyfikacyjne oraz rozterki o zabarwieniu egzystencjalnym. Skomponowane w oparciu o nie wypowiedzi postaci zwykle przybierają typową dla tekstu narracyjnego formę linearną - nadmiernie płynną, pozbawioną wtrąceń, niezakłócaną sygnałami dochodzącymi z otoczenia, różną od tzw. „naturalnej konwersacji”38. Nie stanowi to jednak mankamentu. Przeciwnie - czyni manifestację treści ideowych bardziej dostępną, przejrzystą, w sposób niewymuszony skłania odbiorcę do podjęcia refleksji nad zakodowanym komunikatem, wyjścia poza fabularne ramy, sprzyja wejściu w dialog z określonymi poglądami lub światopoglądami.

Utwory Fietisowa zasadniczo cechuje struktura otwarta. Choć autor nie przytłacza odbiorcy dydaktyzmem i nie narzuca jednej linii interpretacyjnej, to jednak ich ideowa zawartość, jednoznaczna zachęta do refleksji, nie pozostaje wolna od sugestii. Kierunek, w jakim zmierzać mogłyby odpowiedzi na dające o sobie znać pytania, w treści zostaje zaledwie zasygnalizowany. Na pewno nie zabsolutyzowany. Orientację tę można określić mianem ogólnego oblicza relatywizmu - widocznych w przytoczonych fragmentach, wolnych od sądów oceniająco-wartościujących refleksji, których treść uwzględnia tak zwane czynniki relatywizujące. Fietisow podejmuje dialog z odbiorcą bez obaw, że mieszanina dyskursów mogłaby zwieść czytelnika na manowce.

Inny wymiar rzeczonego dialogu, wespół z nim szczegółowe oblicze relatywizmu, ujawnia się poprzez wejście bohaterów w interakcję z teraźniejszością. Wspomniane wyżej problemy samoidentyfikacyjne i wynikająca z nich decyzyjna niedyspozycja - dominująca w planie fabularnym - wymykają się schematycznym,

${ }^{37}$ Е.С. Фетисов, Ковчег ..., op.cit, ss. 195-196.

${ }^{38}$ Zob. F. Poyatos, Literary Anthropology: Toward a New Interdisciplinary Area, [w:] Literary Anthropology. A New Interdisciplinary Approach to People, Signs and Literature, red. F. Poyatos, Amsterdam, Philadelphia, John Benjamins Publishing Company, 1988, ss. 40-41. 
spowszedniałym wyobrażeniom na temat kryzysu tożsamości. Zarówno Fiodor, jak Matwiej żyją w świecie sprzeczności. Pragną z jednej strony wolności, z drugiej muszą sprostać oczekiwaniom innych, nadążyć za nimi. Dodatkowo - obawiają się następstw, konsekwencji, odpowiedzialności za dokonywane wybory. Mało tego, antynomie te podsyca presja na poszukiwanie bądź to autorytetu, który wskaże drogę, bądź punktu odniesienia, który powieściowym bohaterom nada tożsamość. Harmonijną i docelową. A co najważniejsze - jedną jedyną, dzięki której staną się „jacyś”. Fiodor rozumie, że rolę tę spełnić może ukochana kobieta, która go wspiera i okazuje pomoc; z perspektywy Matwieja mogłoby to być dziecko, które niebawem przyjdzie na świat, inaczej mówiąc - radość ojcostwa. Tym sposobem Fietisow $\mathrm{z}$ jednej strony wskazuje na konsekwencje dobrowolnego wyparcia własnej tożsamości, to jest: samozniewolenie, autoinfantylizację, zgodę na statusowe przypisanie pozycji społecznej, swoiste upodobnienie się do „buszującego w zbożu” homososa, którego jakaś niewidzialna ręka zawsze uchroni od upadku - tu rozumianego jako „wolność”, z drugiej zaś na dorastanie, dojrzewanie uznawanego za stracone pokolenia, które z myślą o potomnych dąży do zmiany świata na lepsze i zamiast mnożyć kłopoty zaczyna je przezwyciężać.

Kolejnym, uwidaczniającym się w obu powieściach przejawem relatywizmu, jest - niewyłącznie „rosyjski” - konflikt, wyrażony w przeciwstawieniu indywidualizmowi kolektywizmu. Rozbieżności dwóch skrajnych postaw i wartości autor zdaje się rozstrzygać na korzyść pierwszej z nich. Przesłanie Fietisowa jest bliskie myśli wyrażonej przez Fredericka Coplestona w kontekście zagadnień wysuwanych przez egzystencjalistów, że oto „ideał ludzkiego mrowiska wcale nie jest ideałem każdego i wcale nie jest oczywiste, że człowiek jest jedynie inteligentną mrówką" 39 . Przyjmuje ono znów niezabsolutyzowane wyobrażenie, umożliwiające stawianie budowli wedle własnego uznania, własnych reguł, wielowymiarowe formowanie tożsamości, która przecież nie jest czymś nadanym z góry, ale podlega przekształceniom na skutek różnych nacisków czy zachęt, tak zewnętrznych, jak i wewnętrznych. Co zaś najważniejsze, w takim ujęciu ani jednostki, ani grupy nie ograniczają się do posiadania jednej, wyłącznej tożsamości, ale są w stanie wytworzyć ich kilka, pod wpływem różnych czynników je przedefiniowują, a nawet odrzucają, uznając ich względność w zależności od sytuacji, jako skutek poszukiwania tego, co łączy.

Otwarta pozostaje zaś kwestia odpowiedzi na pytanie, dlaczego Fietisow „swoje prawdy" eksponuje na tle zaburzających percepcję okoliczności, jak alternatywna rzeczywistość (przeszłość, marzenie senne) albo stan chorobowy.

${ }^{39}$ F. Copleston, Filozofia współczesna. Badania nad pozytywizmem logicznym i egzystencjalizmem, tłum. B. Chwedeńczuk, Warszawa, Instytut Wydawniczy PAX, 1981, s. 204. 


\section{Literatura}

Awdiejew A., Habrajska G., Wprowadzenie do gramatyki komunikacyjnej, t. 2, Łask, Oficyna Wydawnicza LEKSEM, 2006, 395 ss.

Bachtin M., Estetyka twórczości stownej, tłum. D. Ulicka, oprac. przekładu i wstęp E. Czaplejewicz, Warszawa, PIW, 1986, 576 ss.

Bachtin M., Problemy poetyki Dostojewskiego, thum. N. Modzelewska, Warszawa, PIW, 1970, 410 ss.

Bachtin M., Stowo w powieści, [w:] Idem, Problemy literatury i estetyki, thum. W. Cesluk-Grajewski, Warszawa, Czytelnik, 1982, ss. 82-277.

Bal M., Narratologia. Wprowadzenie do teorii narracji, tłum. zespół thumaczy ze specjalności przekładowej Instytutu Filologii Polskiej UAM w Poznaniu, Kraków, Wydawnictwo Uniwersytetu Jagiellońskiego, 2012, 263 ss.

Bauman Z., Ptynna nowoczesność, tłum. T. Kunz, Kraków, Wydawnictwo Literackie, 2006, 340 ss.

Brążkiewicz B., Choroba psychiczna w literaturze i kulturze rosyjskiej, Kraków, Księgarnia Akademicka, 2011, 392 ss.

Brążkiewicz B., $W$ zderzeniu z teraźniejszościq. Dialogiczność współczesnej prozy petersburskiej, „Ethos” 2020, nr 1(129), ss. 91-116.

Copleston F., Filozofia współczesna. Badania nad pozytywizmem logicznym i egzystencjalizmem, tłum. B. Chwedeńczuk, Warszawa, Instytut Wydawniczy PAX, 1981, 216 ss.

Custine de A., Listy z Rosji. Rosja w 1839 roku, thum. M. Górski, Kraków, Wydawnictwo Aramis, 1989, 249 ss.

Duda K.A., Szkice o prozie rosyjskiej XXI wieku: Ulicka, Szyszkin, Pielewin, Minajew, Sienczyn, Kuricyn, Starobiniec..., Kraków, Księgarnia Akademicka, 2017, 266 ss.

Erll A., Kultura pamięci. Wprowadzenie, przekł. A. Teperek, posł. i red. nauk. M. Saryusz-Wolska, Warszawa, Wydawnictwa Uniwersytetu Warszawskiego, Niemiecki Instytut Historyczny, 2018, 317 ss.

Mandelsztam O., O naturze słowa, [w:] Idem, Stowo i kultura. Szkice literackie, tłum. i oprac. R. Przybylski, Warszawa, Czytelnik, 1972, ss. 24-41.

Mandelsztam O., Świt akmeizmu, [w:] Idem, Stowo i kultura. Szkice literackie, thum. i oprac. R. Przybylski, Warszawa, Czytelnik, 1972, ss. 181-185.

Markiewicz H., Polifonia, dialogiczność i dialektyka. Bachtinowska teoria powieści, „Pamiętnik Literacki” 1985, nr 76/2, ss. 83-98.

Pankalla A., Doświadczenia graniczne, [w:] Z.W. Dudek, A. Pankalla, Psychologia kultury. Doświadczenia graniczne i transkulturowe, Warszawa, ENETEIA, 2005, ss. 25-164. 
Poyatos F., Literary Anthropology: Toward a New Interdisciplinary Area, [w:] Literary Anthropology. A New Interdisciplinary Approach to People, Signs and Literature, red. F. Poyatos, Amsterdam, Philadelphia, John Benjamins Publishing Company, 1988, ss. 3-49.

Sałajczykowa J., Dziesięciolecie przemian. Proza rosyjska lat 1985-1995, Gdańsk, Wydawnictwo Uniwersytetu Gdańskiego, 1998, 189 ss.

Wołodźko-Butkiewicz A., Od pieriestrojki do laboratoriów netliteratury. Przemiany we wspótczesnej prozie rosyjskiej, Warszawa, Studia Rossica, 2004, 438 ss.

Большакова А., Феноменология литературного письма. Опрозе Бориса Евсеева, Москва, МАКС Пресс, 2004, 142 ss.

Люсый А.П., Московский текст: текстологическая кониепџия русской культуры, Москва, Издательский дом „Вече”, ООО „Русский импульс”, 2013, 320 ss.

Люсый А.П., Поэтика предвосхищения. Россия сквозь призму литературы, литература сквозь призму культурологии: теоретическая комедия, Москва, Товарищество научных изданий КМК, 2011, 570 ss.

Синдаловский Н.А., Словарь петербуржиа. Лексикон Северной столицы. История и современность, Москва, Санкт-Петербург, Издательство Центрполиграф, Русская тройка-Спб, 2014, 635 ss.

Статистические показатели по выпуску печатных изданий, Российская книжная палата, Филиал ИТАР-ТАСС, [w:] http://www.bookchamber.ru/statistics. html [dostęp: 30.05.2021].

Топоров В.Н., Петербургский текст русской литературы, Санкт-Петербург, Искусство-СПБ, 2003, 616 ss.

Фетисов Е., Пас в пустоту, Санкт-Петербург, Издательство «Союз писателей Петербурга», 2014, 240 ss.

Фетисов Е.С., Ковчег, Москва, Время, 2018, 224 ss.

Шульц С.С. (младший), Склярский В.А., Бродячая собака. Век нынешний-век минувший, Санкт-Петербург, Белое и Черное, 2002, 207 ss.

\section{References}

Awdiejew A., Habrajska G., Wprowadzenie do gramatyki komunikacyjnej [Introduction to Communicative Grammar], vol. 2, Łask, Oficyna Wydawnicza LEKSEM, 2006, 395 pp.

Bachtin M., Estetyka twórczości stownej [Aesthetics of Verbal Art], trans. D. Ulicka, E. Czaplejewicz (Ed.), Warszawa, PIW, 1986, 576 pp.

Bachtin M., Problemy poetyki Dostojewskiego [Problems of Dostoevsky's Poetics], trans. N. Modzelewska, Warszawa, PIW, 1970, 410 pp. 
Bachtin M., Stowo w powieści [Word in Novel], [in:] Idem, Problemy literatury i es-tetyki, [Problems of Literature and Aesthetics], trans. W. Cesluk-Grajewski, Warszawa, Czytelnik, 1982, pp. 82-277.

Bal M., Narratologia. Wprowadzenie do teorii narracji [Narratology: Introduction to the Theory of Narrative], translated by Polish Philology Institute translation specialty team, Adam Mickiewicz University in Poznań, Kraków, Wydawnictwo Uniwersytetu Jagiellońskiego, 2012, 263 pp.

Bauman Z., Plynna nowoczesność [Liquid Modernity], trans. T. Kunz, Kraków, Wydawnictwo Literackie, 2006, 340 pp.

Bol'shakova A., Fenomenologiia literaturnogo pis'ma. O proze Borisa Evseeva [Phenomenology of Literary Writing. On the Prose of Boris Evseev], Moscow, MAKS Press, 2004, 142 pp.

Brążkiewicz B., Choroba psychiczna w literaturze i kulturze rosyjskiej [Mental Illness as Seen in Russian Literature and Culture], Kraków, Księgarnia Akademicka, 2011, 392 pp.

Brążkiewicz B., W zderzeniu z teraźniejszościq. Dialogiczność współczesnej prozy petersburskiej [Confronting the Present Time: Dialogic Nature of Contemporary Petersburg Text], "Ethos" 2020, no. 1(129), pp. 91-116.

Copleston F., Filozofia współczesna. Badania nad pozytywizmem logicznym i egzystencjalizmem [Contemporary Philosophy. Studies of Logical Positivism and Existentialism], trans. B. Chwedeńczuk, Warszawa, Instytut Wydawniczy PAX, 1981, 216 pp.

Custine de A., Listy z Rosji. Rosja w 1839 roku [Letters from Russia. Russia in 1839], trans. M. Górski, Kraków, Wydawnictwo Aramis, 1989, 249 pp.

Duda K.A., Szkice o prozie rosyjskiej XXI wieku: Ulicka, Szyszkin, Pielewin, Minajew, Sienczyn, Kuricyn, Starobiniec... [Sketches on Russian Prose of the $21^{\text {st }}$ Century. Ulitskaya, Shishkin, Pelevin, Mineav, Sentchin, Kuritsyn, Starobinets...], Kraków, Księgarnia Akademicka, 2017, 266 pp.

Erll A., Kultura pamięci. Wprowadzenie [Culture of Memory. Introduction], trans. A. Teperek, M. Saryusz-Wolska (Ed.), Warszawa, Wydawnictwa Uniwersytetu Warszawskiego, Niemiecki Instytut Historyczny, 2018, 317 pp.

Fetisov E., Pas v pustotu [Passing Into the Void], Saint Petersburg, Izdatel'stvo "Soyuz pisateley Peterburga", 2014, 240 pp.

Fetisov E.S., Kovcheg [The Ark], Moscow, Vremia, 2018, 224 pp.

Liusyi A.P., Moskovskii tekst: tekstologicheskaia kontseptsiia russkoi kul'tury [Moscow Text: Textological Concept of Russian Culture], Moscow, Izdatel'skii dom "Veche", "Russkii impul's" Ltd., 2013, 320 pp.

Liusyi A.P., Poetika predvoskhishcheniia. Rossiia skvoz' prizmu literatury, literatura skvoz' prizmu kul'turologii: teoreticheskaia komediia [The Poetics of 
Anticipation. Russia through the Prism of Literature, Literature through the Prism of Culturology: A Theoretical Comedy], Moscow, TKMK Scientific Press, 2011, 570 pp.

Mandelszatm O., O naturze słowa [On the Nature of the Word], [in:] Idem, Stowo i kultura. Szkice literackie [Word and Culture. Literary Sketches], trans. R. Przybylski (Ed.), Warszawa, Czytelnik, 1972, pp. 24-41.

Mandelsztam O., Świt akmeizmu [The Dawn of Akmeism], [in:] Idem, Słowo i kultura. Szkice literackie, [Word and Culture. Literary Sketches], trans. R. Przybylski (Ed.), Warszawa, Czytelnik, 1972, pp. 181-185.

Markiewicz H., Polifonia, dialogiczność i dialektyka. Bachtinowska teoria powieści [Polyphony, Dialogicality and Dialectics. Bakhtin's Theory of the Novel], "Pamiętnik Literacki” [Literary Diary] 1985, no. 76/2, pp. 83-98.

Pankalla A., Doświadczenia graniczne [Borderline Experiences], [in:] Z.W. Dudek, A. Pankalla, Psychologia kultury. Doświadczenia graniczne i transkulturowe [Cultural Psychology. Borderline and Transcultural Experiences], Warszawa, ENETEIA, 2005, pp. 25-164.

Poyatos F., Literary Anthropology: Toward a New Interdisciplinary Area, [in:] F. Poyatos (Ed.), Literary Anthropology. A New Interdisciplinary Approach to People, Signs and Literature, Amsterdam, Philadelphia, John Benjamins Publishing Company, 1988, pp. 3-49.

Sałajczykowa J., Dziesięciolecie przemian. Proza rosyjska lat 1985-1995 [A Decade of Transformations. Russian Prose of 1985-1995], Gdańsk, Wydawnictwo Uniwersytetu Gdańskiego, 1998, 189 pp.

Shul'ts S.S. (junior), Skliarskii V.A., Brodiachaia sobaka. Vek nyneshnii - vek minuvshii [The Stray Dog. The Present and the Past], Saint Petersburg, Beloe i Chernoe Publ., 2002, 207 pp.

Sindalovskii N.A., Slovar'peterburzhtsa. Leksikon Severnoi stolitsy. Istoriia i sovremennost'[Dictionary of a Petersburger. Lexicon of the Northern Capital. History and Modernity], Moscow, Saint Petersburg, Izdatel'stvo Tsentrpoligraf, Russkaia troika-Spb, 2014, 635 pp.

Statisticheskie pokazateli po vypusku pechatnykh izdanii [Statistical Indicators for the Production of Printed Publications], Russian Book Chamber, Brench of ITAR-TASS. Available at: http://www.bookchamber.ru/statistics.html [accessed: 30.05.2021].

Toporov V.N., Peterburgskii tekst russkoi literatury [Petersburg Text of Russian Literature], Saint Petersburg, Iskusstvo-SPB, 2003, 616 pp.

Wołodźko-Butkiewicz A., Od pieriestrojki do laboratoriów netliteratury. Przemiany we współczesnej prozie rosyjskiej [From Perestroika to Laboratories of Netliterature. Transformations in Contemporary Russian Prose], Warszawa, Studia Rossica, 2004, 438 pp. 